\title{
THE ROLE OF VORTEX SHEDDING IN THE TRAILING EDGE LOSS OF TRANSONIC TURBINE BLADES
}

\author{
A. P. Melzer ${ }^{1}$ and G. Pullan ${ }^{2}$ \\ Whittle Laboratory \\ University of Cambridge \\ $1 \mathrm{JJ}$ Thomson Avenue \\ Cambridge, CB3 ODY, UK
}

\begin{abstract}
The loss of Square, Round, and Elliptical turbine trailing edge geometries, and the mechanisms responsible, is assessed using a two-part experimental program. In the first part, a single blade experiment, in a channel with contoured walls, allowed rapid testing of a range of trailing edge sizes and shapes. In the second part, turbine blade cascades with a sub-set of sizes of the trailing edge geometries tested in part one were evaluated in a closed-loop variable density facility, at exit Mach numbers from 0.40 to 0.97 , and exit Reynolds numbers from $1.5 \times 10^{5}$ to $2.5 \times 10^{6}$. Throughout the test campaign, detailed instantaneous Schlieren images of the trailing edge flows have been obtained to identify the underlying unsteady mechanisms in the base region. The experiments reveal the importance of suppressing transonic vortex shedding, and quantify the influence of this mechanism on loss. The state and thickness of the blade boundary layers immediately upstream of the trailing edge are of critical importance in determining the onset of transonic vortex shedding. Elliptical trailing edge geometries have also been found to be effective at suppressing transonic vortex shedding. For trailing edges that exhibit transonic vortex shedding, a mechanism is identified whereby reflected shed shockwaves encourage or discourage vortex shedding depending on the phase with which the shocks return to the trailing edge, capable of modifying the loss generated.
\end{abstract}

\section{INTRODUCTION}

Blunt trailing edges, often present behind turbine blades for thermal, mechanical, or manufacturing reasons, are known to shed vortices and form Von Kármán vortex street wakes [1, 2]. At Mach numbers between 0.5 and 1.0, shockwaves have been observed to be shed with each shed vortex [3, 4]. Figure 1 shows a typical Schlieren image of vortex shedding behind a round trailing edge at Mach 0.65. While much is known about the influence of the trailing edge shape and boundary layers on

\footnotetext{
${ }^{1}$ Now of Rolls-Royce plc, Derby, DE24 8BJ, UK

${ }^{2}$ Corresponding Author: G. Pullan, gp10006@cam.ac.uk
}

subsonic trailing edges $[1,5,6]$ less information is available on transonic trailing edges, which is the focus of the present work.

Denton [7] stated that trailing edges typically contribute $1 / 3^{\text {rd }}$ of the profile loss of turbine blades, though figures as high as $70 \%$ of the profile losses have been recorded for certain blade designs [8]. We will show that when transonic vortex occurs it is a dominant loss generating mechanism.

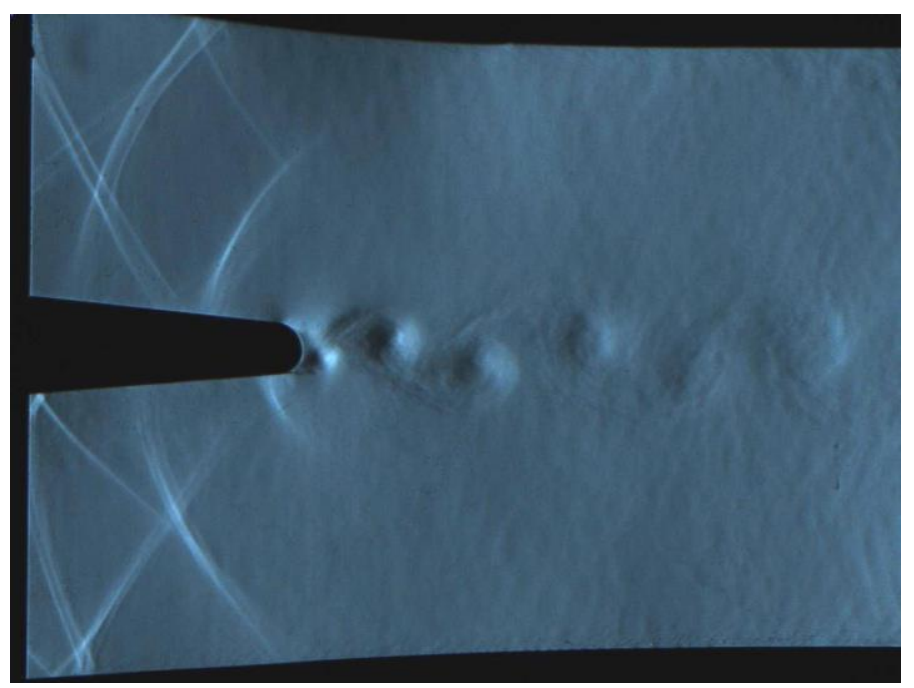

Fig. 1 - Schlieren image of vortex shedding behind a round trailing edge at Mach 0.65

We first provide, using Schlieren images from the present work, and referring to the work of Sieverding et al. [9], a detailed description of vortex shedding and the formation of shed shockwaves. Figure 2 shows a series of close-up images at equal intervals through a vortex shedding cycle, for the same trailing edge and Mach number as Fig. 1 (Round, Mach 0.65, te/o $=7.8 \%)$. These images are taken from a set of over 100 such images, taken at random time intervals, and placed in order by measuring the positions of the shockwaves. 


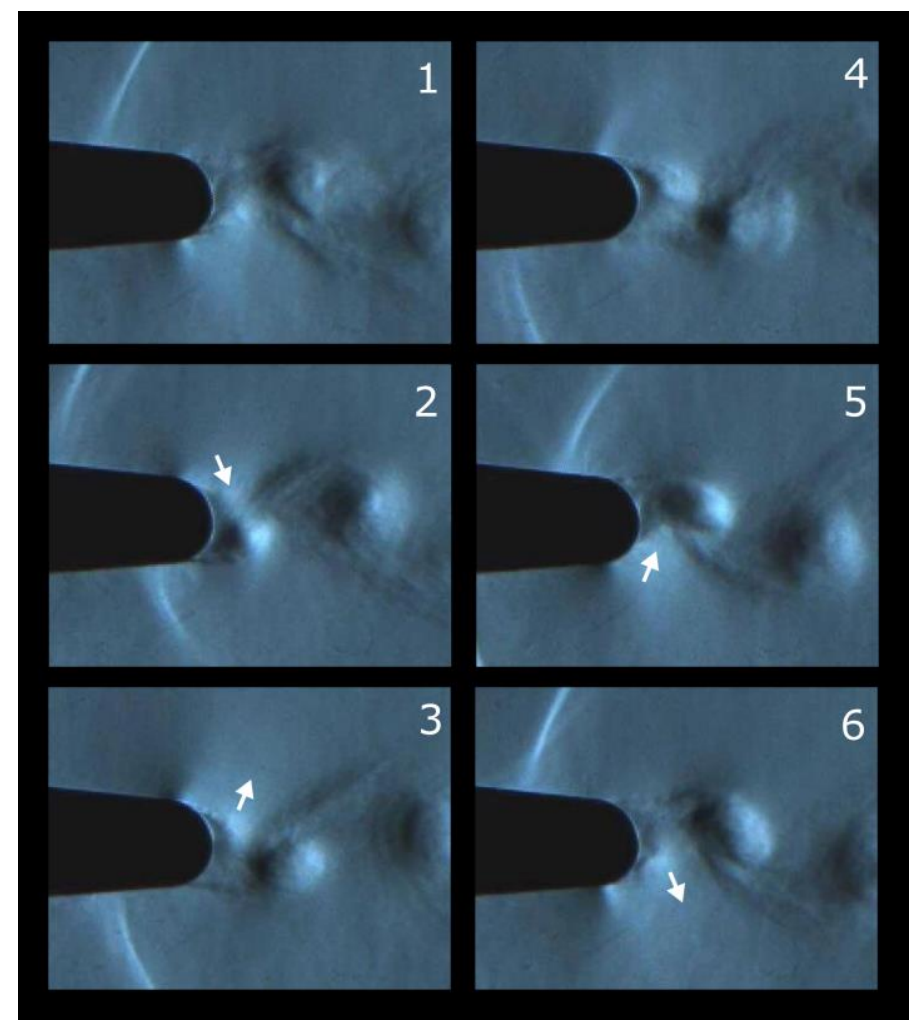

Fig. 2 - Schlieren images spaced at equal time intervals around a vortex shedding cycle, behind a Round trailing edge (of te/o $=7.8 \%$ ) at Mach 0.65 . Image 6 is a repeat image at the same phase as image 1 . Arrows indicate shear layer motion at key points.

The shear layers, originating from the separation points on either side of the trailing edge, alternately expand into the base region, and roll up to form vortices. This expansion is accompanied by an inwards motion of the shear layer, highlighted by the arrows in images 2 and 5 of Fig. 2. The forming vortex will continue to grow until it reaches a critical size, when it will shed and move away from the trailing edge, pushing the shear layer from which it originated outwards, as indicated by the arrows in images 3 and 6 of Fig. 2. This outwards movement of the shear layer sends a pressure wave upstream, through the expansion from which the vortex originated. If, due to the small radius of curvature of the flow around the trailing edge, the expansion into the base region is supersonic, the upstream moving pressure wave will form a shockwave that will then propagate out into the freestream, as seen in Fig. 2. The potential presence of supersonic isentropic Mach numbers in the alternate expansions into the trailing edge region was confirmed using unsteady surface pressure measurements around a round trailing edge by Sieverding et al. [9]. This mechanism explains the presence of shockwaves in an otherwise subsonic flow, demonstrating that vortex shedding which exhibits shed shockwaves is transonic, involving both subsonic and supersonic flow. To make a distinction, for the remainder of this paper, vortex shedding involving supersonic expansions and the resultant characteristic shed shockwaves will be referred to as "transonic vortex shedding", as opposed to "subsonic vortex shedding", which involves subsonic expansions and so no shed shockwaves.

The present work aims to assess the influence of trailing edge geometry, and the boundary layers present at the trailing edge, on transonic vortex shedding. Trailing edge geometry is of interest as there are unexplained differences between results in the current literature, such that minimum loss trailing edge geometries for different trailing edge conditions (Mach number, Reynolds number, and boundary layers) are hard to determine. For example, Nash et al. [4] found that the base pressure of Round trailing edges was lower than that of Square trailing edges at Mach numbers over 0.55 (and thus the loss of Round trailing edges is higher), whereas Prust and Helon [10] found that though the loss differences between Square and Round trailing edges narrowed at Mach numbers over 0.55, the Round trailing edges still had lower loss. Therefore, during the present work, a range of turbine representative sizes of Square, Round and also Elliptical trailing edges have been tested at typical turbine operating conditions, in order to assess the influence of trailing edge geometry on the loss and flow structure behind turbine trailing edges.

For subsonic vortex shedding it is known that thicker boundary layers relative to the trailing edge size reduce the trailing edge loss [1, 6, 11]. Information on the effects of boundary layers on transonic vortex shedding is, however, difficult to find in the literature, with the only extensive study known to the authors being that of Sieverding and Heinemann [12], which focused on shedding frequency rather than loss or base pressure. It will be shown that some of the unexplained differences between results in the prior literature, including the differences between Nash et al. [4] and Prust and Helon [10], can be explained by the impact of different boundary layer thicknesses and states on the trailing edge flow.

\section{APPROACH}

A two step experimental program was devised to achieve the aims of the work. First, following Sieverding, $\mathrm{Xu}$, and Deckers $[13,14,15]$ a single blade experiment was used, called the Isolated Trailing Edge Rig. Second, a four passage cascade for use in the Whittle Laboratory High Speed Tunnel was designed, called the Cascade Rig. The first experiment was designed to allow many trailing edges to be tested quickly, while the second was used to test a subset of trailing edges under the more turbine representative conditions of a cascade.

All tests used an $11^{\circ}$ trailing edge wedge angle, representative of modern cooled turbine designs. Square, Round, and Elliptical trailing edges were tested in both rigs. All the Elliptical trailing edges tested had 2:1 major : minor axis ratios.

The trailing edges tested are compared using Kinetic Energy loss coefficients calculated from mixed out quantities using Eq. 1.

$$
\zeta=\frac{E_{k 2 i s}-E_{k 2 m i x}}{E_{k 2 i s}}=1-\frac{E_{k 2 m i x}}{E_{k 2 i s}}=1-\frac{\left(T_{02 m i x}-T_{2 m i x}\right)}{\left(T_{01}-T_{2 i s}\right)}
$$




\section{Isolated Trailing Edge Rig}

Figure 3 shows a diagram of the Isolated Trailing Edge Rig. The rig consists of a single $3 \mathrm{D}$ printed blade mounted between liners, powered by the transonic vacuum facility originally designed by $\mathrm{Xu}$ [14]. Provision is made for Schlieren images of the trailing edge flow, surface pressure measurements on the blade, boundary layer traverses, and line traverses through the wake at $42 \%$ of axial chord downstream of the trailing edge. The liners are shaped to impose a pressure distribution on the plate similar to that of a real turbine blade, with different profiles on the top and bottom to mimic a pressure and suction surface. Figure 4 shows the equivalent volume in a cascade that the Isolated Trailing Edge Rig is designed to represent. The key numerical parameters of the Isolated Trailing Edge Rig are summarized in Table 1. For the Isolated Trailing Edge Rig the throat (o) is defined as the minimum distance between the liners in the rig downstream of the trailing edge.

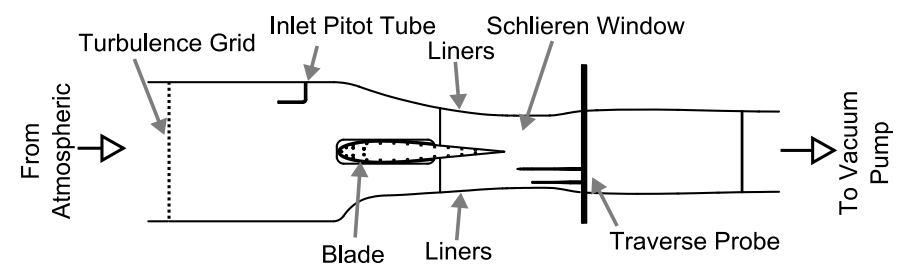

Fig. 3 - Diagram of the Isolated Trailing Edge Rig

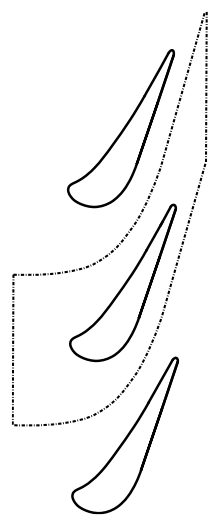

Fig. 4 - Diagram of equivalent volume in a cascade that the Isolated Trailing Edge Rig is designed to represent

The exit traverse probe of the Isolated Trailing Edge Rig combines a Pitot tube and a static tube on one stem, designed in accordance with Ower and Pankhurst [16]. The total estimated uncertainty in $\mathrm{KE}$ loss coefficients calculated using the traverse probe data is $\Delta \zeta= \pm 0.001$, based on the maximum discrepancy in repeat measurements on the same trailing edge.

The Schlieren apparatus used to image the trailing edge flow was a triple folded Z-type system, necessary to fit in the available space. A LED flash light-source based on that of Willert et al. [17] producing $1 \mu \mathrm{s}$ flashes was used in conjunction with a CCD camera to capture instantaneous images of the flow. It was found that a vertical graded filter, which identifies horizontal density gradients, was best for imaging the shockwaves and vortices of interest. The same graded filter is used for all the Schlieren images from the Isolated Trailing Edge Rig in the present work.

Table 1 - Isolated Trailing Edge Rig Details

\begin{tabular}{lr}
\hline \hline TE Mach number $\left(\mathrm{M}_{\mathrm{te}}\right)$ & $0.30-0.95$ \\
Inlet Mach number $\left(\mathrm{M}_{1}\right)$ & $0.27-0.30$ \\
Blade Reynolds number $\left(\mathrm{Re}_{2}\right)$ & $0.6 \times 10^{6}-1.4 \times 10^{6}$ \\
Max Blockage $\left(\mathrm{te}_{\mathrm{max}} / \mathrm{o}\right)$ & $7.8 \%$ \\
TE wedge angle & $11^{\circ}$ \\
Chord/throat (te/o, "Sharp" blade) & 2.5 \\
Blade aspect ratio & 0.33 \\
Inlet Turbulence $(\mathrm{Tu})$ & $6 \%$ \\
\hline \hline
\end{tabular}

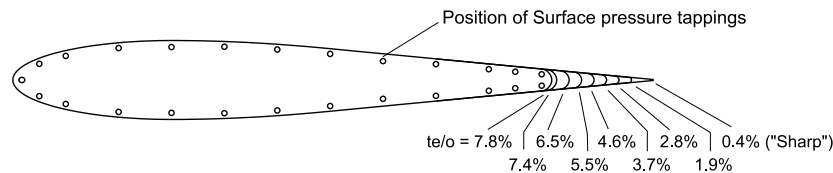

Fig. 5 - Range of Round trailing edges tested in the Isolated Trailing Edge Rig

Figure 5 shows the range of eight sizes of Round trailing edge tested in the Isolated Trailing Edge Rig, and the nominal reference sharp trailing edge. The nominal reference sharp trailing edge in fact had a thickness of approximately $0.4 \%$ of throat, corresponding to the minimum feature size of the $3 \mathrm{D}$ printing process used. For Square and Elliptical trailing edges a subset of the range of sizes of Round trailing edges were tested, summarized in Table 2. The Square and Elliptical trailing edges are designed such that the maximum thicknesses of the trailing edges are matched to those of the Round trailing edges, as per Fig. 6.

Table 2 - Range of TE sizes tested

\begin{tabular}{lcccccccc}
\hline \hline Shape & \multicolumn{7}{c}{ Sizes (te/o)/\% } \\
\hline Round & 7.8 & 7.4 & 6.5 & 5.5 & 4.6 & 3.7 & 2.8 & 1.9 \\
Square & 7.8 & & & 5.5 & & 3.7 & & 1.9 \\
Elliptical & & 7.4 & & 5.5 & & 3.7 & & \\
\hline \hline
\end{tabular}

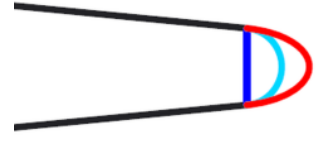

Fig. 6 - Comparison of Square, Round and Elliptical trailing edge geometries tested in the Isolated Trailing Edge Rig.

\section{Cascade Rig}

The Cascade Rig consists of a four passage linear cascade installed in the High Speed Tunnel at the Whittle Laboratory. 
The High Speed Tunnel is a continuous variable density facility, described by Gostelow and Watson [18]. Table 3 gives the key details of the Cascade Rig.

Table 3 - Cascade Rig Details

\begin{tabular}{lr}
\hline \hline No. Passages & 4 \\
Nominal Chord $\left(\mathrm{c}_{\mathrm{nom}}\right)$ & $\approx 100 \mathrm{~mm}$ \\
Axial Chord $\left(\mathrm{c}_{\mathrm{ax}} / \mathrm{c}_{\mathrm{nom}}\right)$ & $\approx 0.44$ \\
Aspect Ratio & $\approx 1$ \\
Throat Size $\left(\mathrm{o} / \mathrm{c}_{\mathrm{nom}}\right)$ & $\approx 0.19$ \\
Pitch : Chord ratio & $\approx 0.85$ \\
Inlet Angle & $0^{\circ}$ \\
Exit Angle & $\approx 75^{\circ}$ \\
TE wedge angle & $11^{\circ}$ \\
Exit Mach number $\left(\mathrm{M}_{2 \mathrm{is}}\right)$ & $0.40-0.97$ \\
Inlet Stagnation pressure $\left(\mathrm{P}_{01}\right)$ & $0.1-2 \mathrm{bar}$ \\
Exit Reynolds number range $\left(\mathrm{Re}_{2}\right):$ & \\
$\quad$ at $\mathrm{M}_{2 \text { is }}=0.90$ & $140,000-2,600,000$ \\
$\quad$ at $\mathrm{M}_{2 \text { is }}=0.40$ & $80,000-1,500,000$ \\
Inlet Turbulence $(\mathrm{Tu})$ & $4 \%$ \\
\hline \hline
\end{tabular}

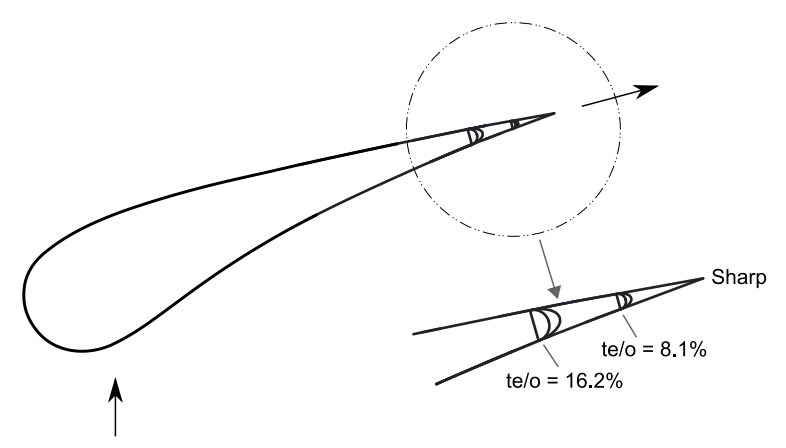

Fig. 7 - Sketch of Cascade Rig trailing edges

To measure loss, mid-span exit traverses were performed $25 \%$ of axial chord downstream of the blades. This was done using a Neptune probe, designed following Sieverding and Maretto [19]. This probe was calibrated at Mach numbers from 0.30 to 1.10 , yaw angles between $\pm 20^{\circ}$, and Reynolds numbers (based on the cascade nominal chord) from $1.4 \times 10^{5}$ to $2.8 \times 10^{6}$, using a calibration process similar to that of Dominy and Hodson [20]. The estimated uncertainty of KE loss coefficients for the Cascade Rig is $\Delta \zeta \approx \pm 0.001$ at cascade Reynolds numbers above $1 \times 10^{6}$, rising linearly with Reynolds number below $\operatorname{Re}_{2}=1 \times 10^{6}$ to $\Delta \zeta \approx \pm 0.0025$ at $\operatorname{Re}_{2}=1.5 \times 10^{5}$.

Due to space restrictions around the High Speed Tunnel a compact Newtonian on-axis Schlieren system was used. This system is anastigmatic, allowing the use of a colored filter to image both horizontal and vertical density gradients. An example of the filter used is included in the top right corner of each Schlieren image presented of the cascade. In common with the Isolated Trailing Edge Rig, this apparatus again used the $1 \mu \mathrm{s}$ LED flash light-source combined with a color CCD camera.

In the Cascade Rig, two sizes each of Square, Round and Elliptical trailing edges were tested, shown on Fig. 7. These sizes were $16.2 \%$ and $8.1 \%$ of throat; these values are rounded to $16 \%$ and $8 \%$ on figures to save space.

\section{TRANSONIC VORTEX SHEDDING SHOCKWAVE INTERFERENCE}

First in the Isolated Trailing Edge Rig, and later in the Cascade Rig, an unexpected phenomenon of reflected shockwaves interfering with vortex shedding behind Square and Round trailing edges was observed. Shockwave interference effects were first noticed through the appearance of peaks and troughs in the loss coefficients of Square and Round trailing edges, when plotted against Mach number, as shown on Fig. 8 .
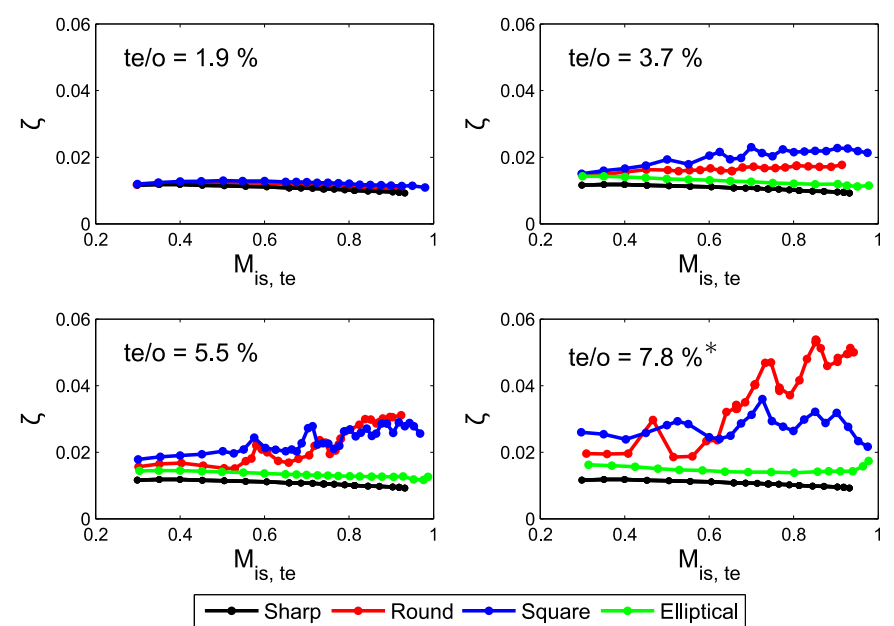

Fig. 8 - KE loss plotted against Mach number for Square, Round and Elliptical trailing edges of different sizes, from the isolated trailing edge rig, with the sharp trailing edge included for reference. (*Elliptical trailing edge has te/o = 7.4\%)

Figure 9 shows a sequence of 6 images equally spaced through a shedding cycle of the te/o $=7.8 \%$ Round trailing edge at an exit Mach number of 0.737 , near the second peak of the KE loss coefficient data for this trailing edge on Fig. 8. Tracking the shockwaves around the cycle from image to image, it is found that a shockwave shed from the suction surface reflects off the outer wall suction surface liner (the lower liner), and returns at just the right moment to cross the wake and combine with the shockwave forming on the pressure side two cycles later (i.e. it returns to the trailing edge region with a phase lag of 2.5 cycles). The same is true with the sides reversed for shockwaves shed from the pressure side (upper side). The returning shockwave arrives at the trailing edge at just the moment a vortex sheds and the shear layers switch direction, such that the motion of the returning shockwave is in phase with the motion of the trailing edge shear layers. This 
encourages vortex shedding, thereby causing a peak in kinetic energy loss, as observed on Fig. 8.

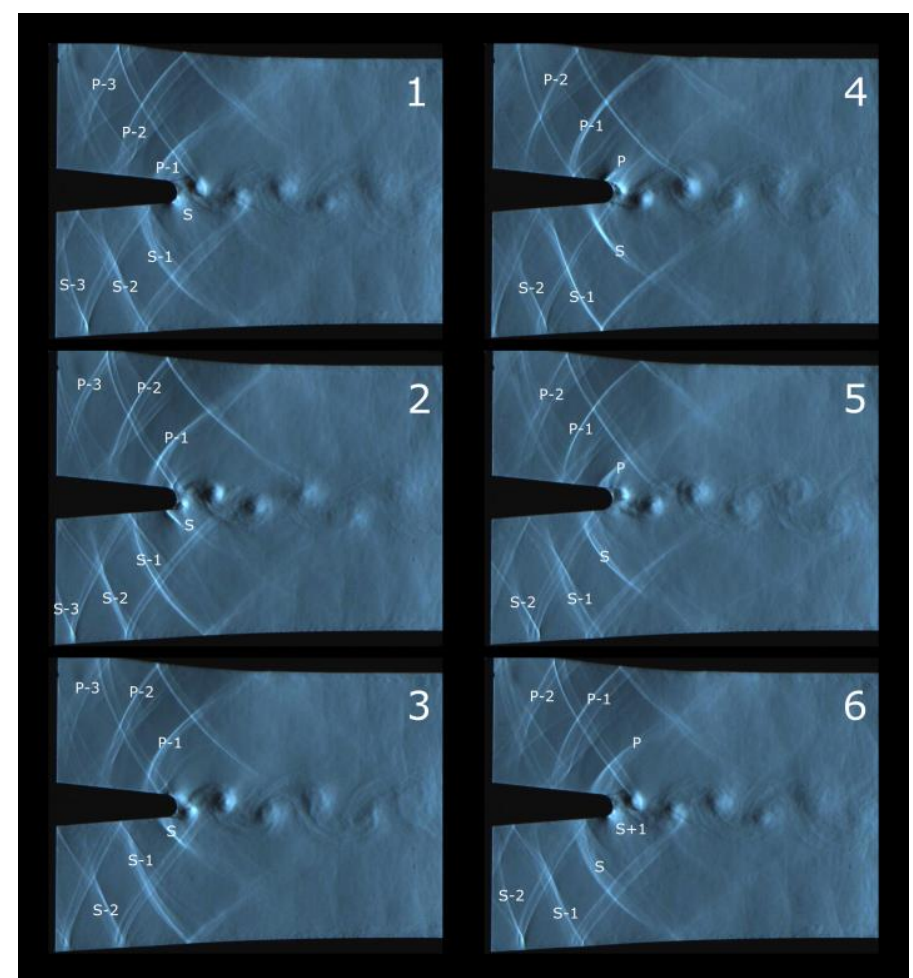

Fig. 9 - Ordered sequence of Schlieren images for the ITE Round $\mathrm{TE}$ of te/o $=\mathbf{7 . 8 \%}$, at $\mathrm{M}_{\mathrm{te}}$, is $=\mathbf{0 . 7 3 7}$. The sequence starts at the point of formation of a shock on the suction side, labeled S. S-1, S-2 and S-3 are the shocks shed 1, 2, and 3 cycles ago respectively. The shocks shed from the pressure side are similarly labeled P, P-1, P-2, and P-3; Image 6 is the same as image 1 , with the labels incremented by 1 cycle.

Figure 10 shows a similar sequence of images to Fig. 9 for the same te/o $=7.8 \%$ Round trailing edge at a higher trailing edge Mach number of 0.80. Mach 0.80 is within the loss trough after the peak corresponding to Fig. 9. In these images it can be observed that reflected shockwaves return to the trailing edge with a phase lag of 3 cycles, at the right moment to meet a newly formed shock on the side it was shed from. Hence the shockwaves now return at a moment when they are moving in the opposite direction to the motion of the shear layers, discouraging vortex shedding, and thereby reducing the kinetic energy loss, as observed on Fig. 8.

For the mechanism described above, causing the observed loss peaks and troughs, the reflected shockwave return phase lag determines the Mach numbers at which loss peaks or troughs occur. As the freestream Mach number increases, the shed shockwaves are increasingly swept back by the oncoming flow, such that the phase lag of the returning shockwaves increases with Mach number. Figure 11 illustrates this. For a given size of trailing edge, as the exit Mach number increases, the number of shockwaves present across the passage increases, indicating greater shockwave return cycle phase lags. As the phase lag increases with Mach number, a succession of peaks and troughs are formed. It is observed that the magnitude of the loss changes caused by the returning shockwaves reduces as the phase lag of the returning shockwaves increases, such that peaks and troughs become hard to identify in the loss data on Fig. 8 for vortex shedding cycle phase lags above 5 cycles.

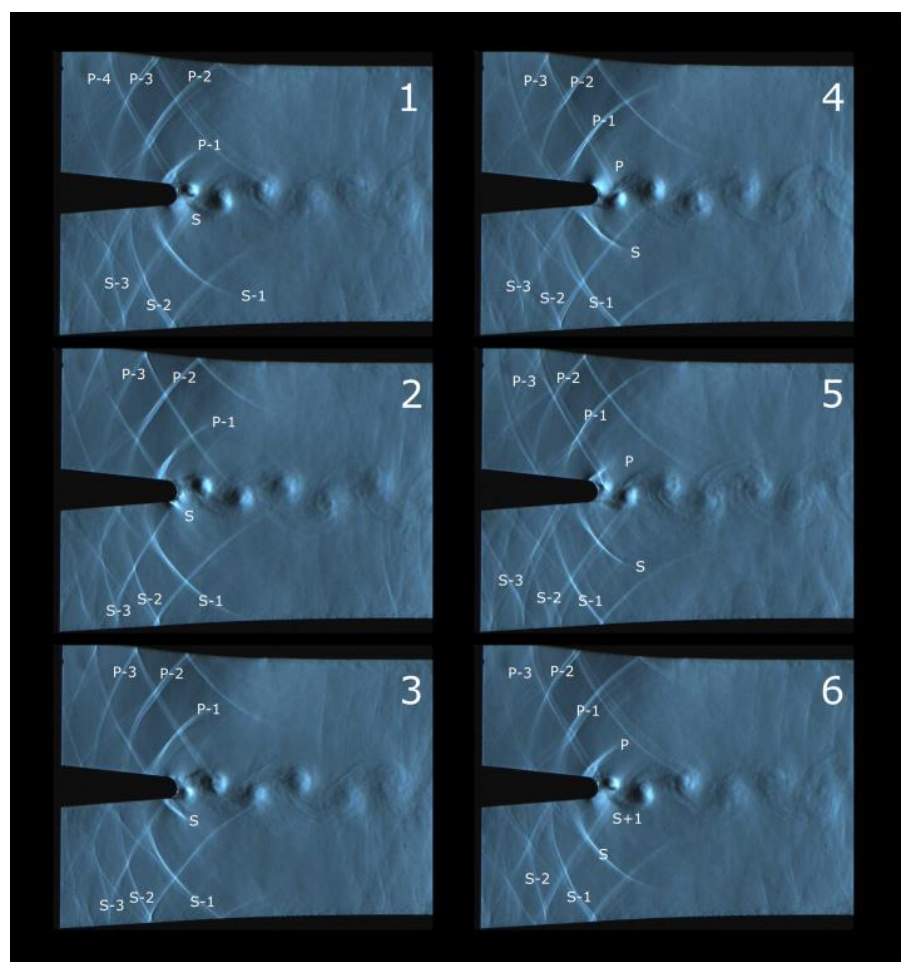

Fig. 10 - Ordered sequence of Schlieren images for the ITE Round $\mathrm{TE}$ of te/o $=\mathbf{7 . 8 \%}$, at $\mathrm{M}_{\mathrm{te}}$, is $=\mathbf{0 . 8 0}$. The sequence starts at the point of formation of a shock on the suction side, labeled S. S-1, S-2 and S-3 are the shocks shed 1, 2, and 3 cycles ago respectively. The shocks shed from the pressure side are similarly labeled P, P-1, P-2, and P-3; Image 6 is the same as image 1, with the labels incremented by 1 cycle.

The shockwave reflections experienced by a trailing edge in the Isolated Trailing Edge Rig are not the same as those experienced by a trailing edge in a cascade. In particular, in the Isolated Trailing Edge Rig reflections are present on both sides whereas, in a cascade, reflections are only present on the pressure side of the trailing edge, with the reflection occurring from the suction surface of the adjacent blade. The Cascade Rig results do show the presence of peaks and troughs, corresponding to the same shockwave cycle phase lags on the Schlieren images as observed in the Isolated Trailing Edge Rig, indicating that a single reflection is sufficient for this phenomenon to occur 


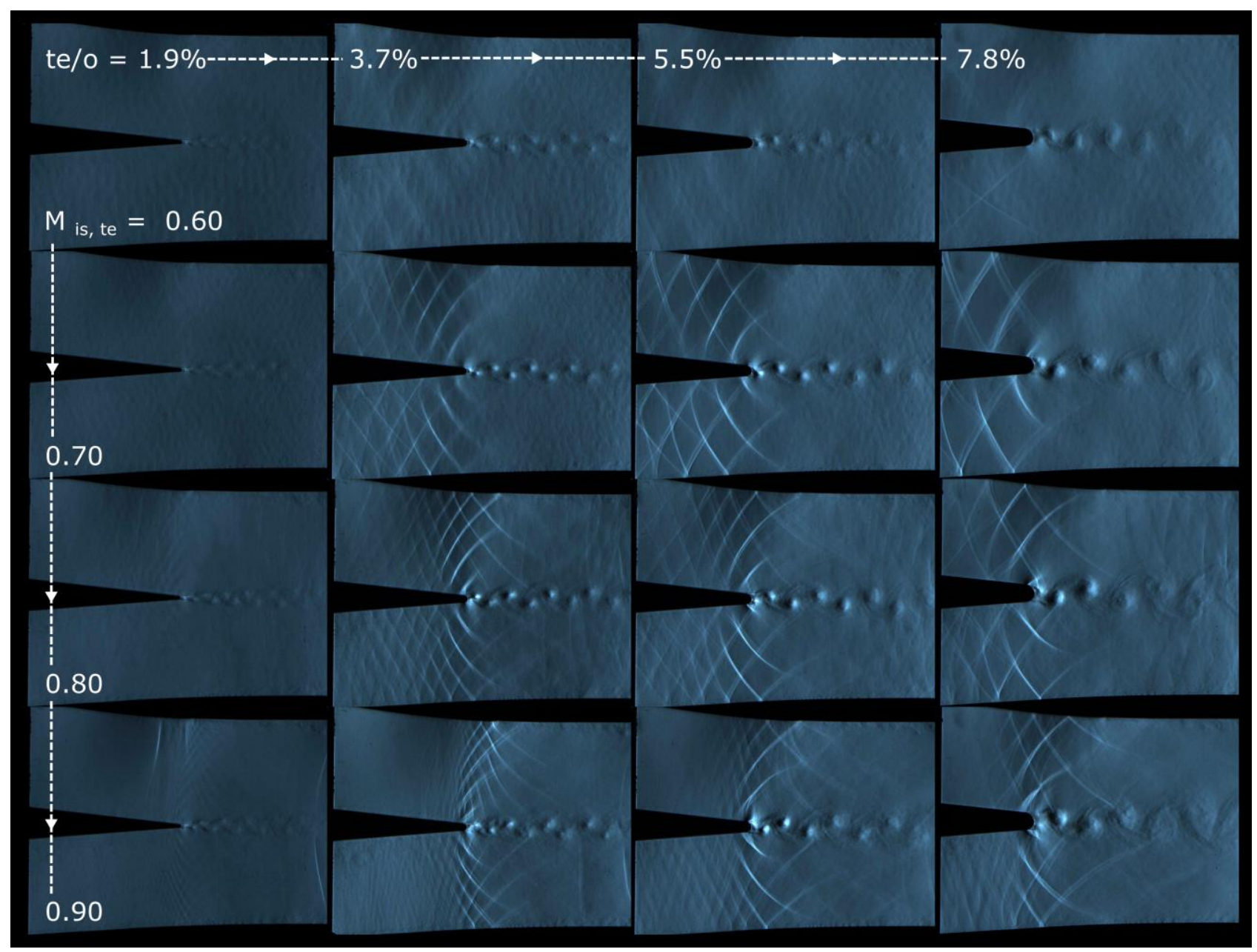

Fig. 11 - Schlieren images of a range of sizes of Round trailing edges from the Isolated Trailing Edge Rig at exit Mach numbers from 0.6 to 0.9

Figure 12 shows plots of loss against Mach number for the Cascade Rig trailing edges at a fixed inlet stagnation pressure of 2.0 bar. For the $16.2 \%$ of throat Round trailing edge a clear peak and trough is visible at around Mach 0.85. Schlieren images show that the peak corresponds to a 3.5 cycle phase lag, while the trough corresponds to 4.0 cycle phase lag. Loss peaks and troughs are less distinct for the $16.2 \%$ of throat Square trailing edge, however the two loss 'steps' at Mach 0.75 and Mach 0.85 correspond to 3.5 cycle and 4.5 cycle reflected shockwave phase delay, as observed on the Schlieren images, indicating that though small in magnitude they are in fact peaks and troughs of the same sort observed in the Isolated Trailing Edge Rig. Examining the prior literature, at least one example of unexplained loss peaks and troughs of transonic turbine blades that could be explained by the mechanism detailed here is found in Gostelow's Cascade Aerodynamics book [21].

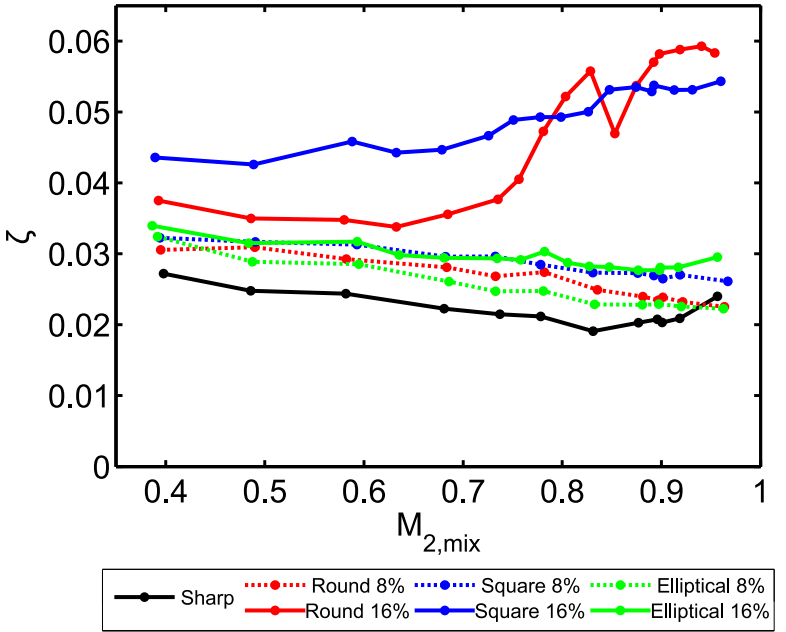

Fig. 12 - KE loss plotted against Mach number for the Cascade Rig trailing edges, at the maximum inlet Stagnation pressure of 2.0 bar. $\left(\operatorname{Re}_{2 c}=1.5 \times 10^{6}\right.$ at $M_{2, \text { mix }}=0.40$, rising to $2.5 \times 10^{6}$ at $\left.M_{2, \operatorname{mix}}=0.90\right)$. 


\section{INFLUENCE OF ISOLATED TRAILING EDGE RIG BOUNDARY LAYERS AND TRAILING EDGE SHAPES}

In order to separate the underlying effects of trailing edge shape and boundary layers from the peaks and troughs identified in the previous section, lines of best fit have been fitted to the data, to smooth out the effects of the peaks and troughs, shown on Fig. 13. These lines of best fit are used when plotting loss against trailing edge thickness for the Isolated Trailing Edge Rig data, to show the underlying trends more clearly.
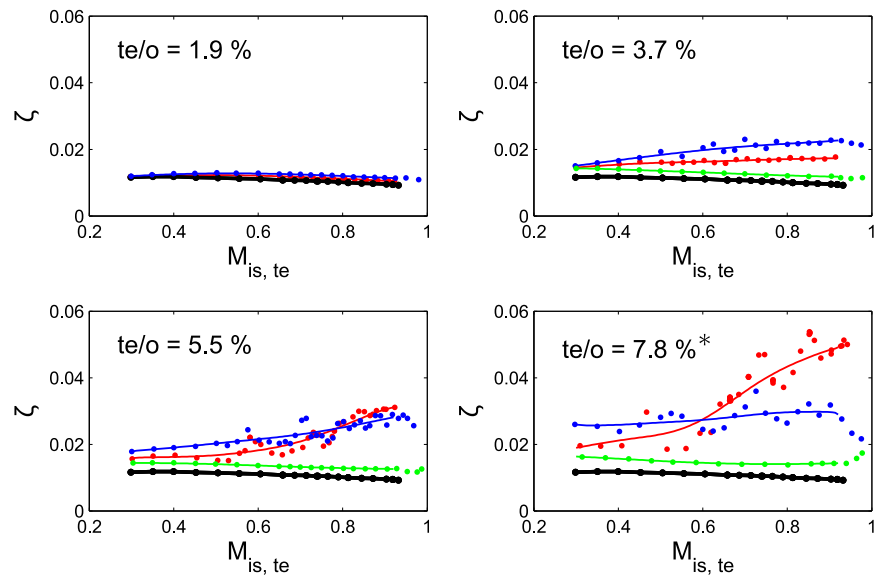

$$
\rightarrow \text { Sharp } \rightarrow \text { Round } \rightarrow \text { Square } \longrightarrow \text { Elliptical }
$$

Fig. 13 - KE loss plotted against Mach number for Square, Round and Elliptical trailing edges of different sizes, and the Sharp trailing edge, from the Isolated Trailing Edge Rig, with lines of best fit. (*Elliptical trailing edge has te/o $=7.4 \%$ )

Influence of Boundary Layer Thickness on Round Trailing Edges

To investigate the influence of boundary layers in the Isolated Trailing Edge Rig a trip-wire was added to the suction surface, to thicken the suction surface boundary layer relative to the trailing edge. This trip was positioned near the leading edge, at $4 \%$ of chord along the blade. Figure 14 shows the pressure and suction surface boundary layer momentum thickness and shape factor plotted against Mach number, from boundary layer profiles measured by a flattened Pitot. At Mach 0.90 , the suction surface trip wire approximately doubles the thickness of the suction surface boundary layer, without significantly affecting the shape factor.

Figure 15 shows the trailing edge loss $\zeta_{\text {te }}$ (calculated as the difference between the overall loss and the loss of the sharp trailing edge blade) plotted against the trailing edge thickness, for both tripped and un-tripped suction surface boundary layers. First, we examine the loss without the trip wire. Trailing edges smaller than te $/ \mathrm{o}=3 \%$ generate less loss per unit thickness, and are less sensitive to the flow Mach number, than trailing edges larger than te/o $=3 \%$. Examining the Schlieren images on Fig. 11 , it can be seen that the shed shockwaves from the te/o = 1.9\% trailing edge appear weaker than those of the thicker trailing edges, judged by the imaged density gradients. These findings can be explained by the boundary layers being sufficiently thick, relative to the trailing edge, to dampen vortex shedding from smaller trailing edges. By dampening vortex shedding the boundary layers either prevent transonic vortex shedding, or weaken it, such that less loss is generated. In addition, as the trailing edge gets smaller relative to the boundary layers, more of the fluid entrained into the vortex street will be boundary layer fluid, which has less kinetic energy to lose.
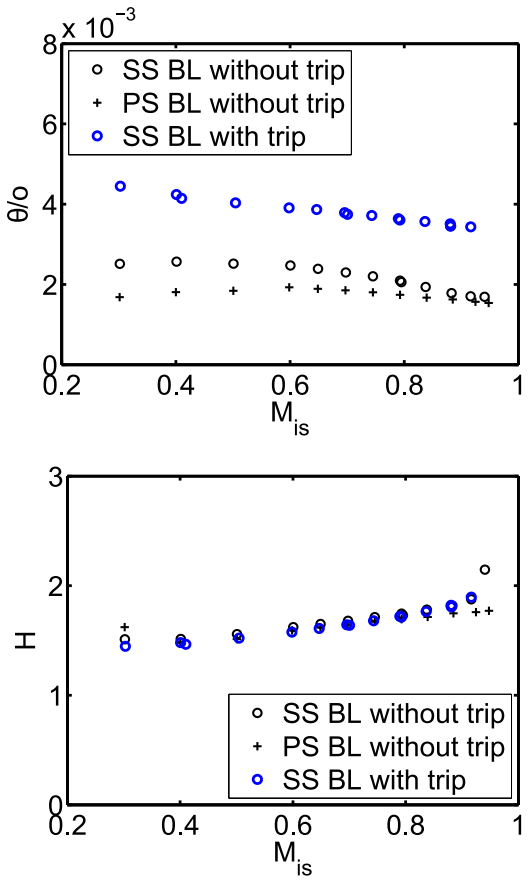

Fig. 14 - Boundary layer momentum thickness and shape factor in the Isolated Trailing Edge Rig, with and without suction surface trip.

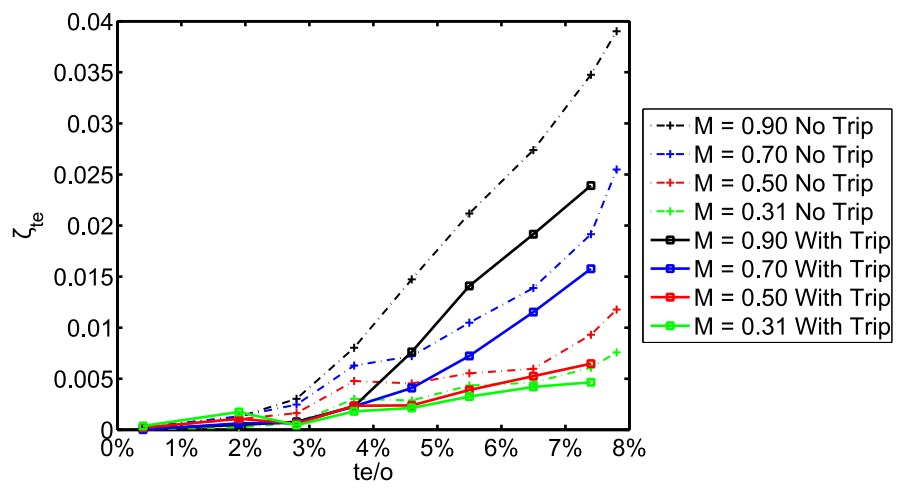

Fig. 15 - Trailing edge loss $\left(\zeta_{\text {te }}\right)$ plotted against te/o for the Isolated Trailing Edge Rig Round trailing edges, with and without a suction surface trip-wire.

On Fig. 15, with the suction surface trip wire, and therefore a thicker suction surface boundary layer, lower loss boundary 
layer dominated trailing edge flow is maintained to a higher trailing edge thickness of approximately te/o $=4 \%$, as would be expected from the above explanation.

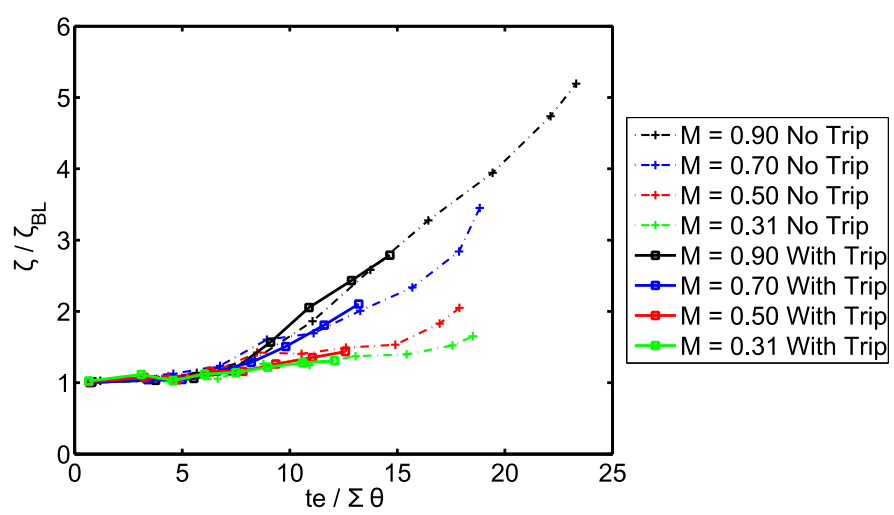

Fig. 16 - Loss scaled by boundary layer loss plotted against trailing edge thickness scaled by the sum boundary layer momentum thickness, for Round trailing edges in the Isolated Trailing Edge Rig.

Figure 16 plots the overall blade loss, normalized by the boundary layer loss, against the trailing edge thickness relative to the sum boundary layer momentum thickness. Using this scaling agreement is achieved between the measured loss of the Round trailing edges with and without trip-wires. This implies that $\operatorname{te} / \Sigma \theta$ captures the underlying physics governing the influence of boundary layers of the type encountered in the Isolated Trailing Edge on the trailing edge flow. Figure 16 shows that, for boundary layers similar to those present in the Isolated Trailing Edge Rig, if the trailing edge thickness is less than seven times the sum momentum thickness of the boundary layers the boundary layers are sufficiently thick to prevent transonic vortex shedding from increasing the loss of the trailing edge.

\section{Isolated Trailing Edge Rig Square vs Round Trailing Edges}

At Mach numbers over 0.60 , for trailing edges behind which transonic vortex shedding occurs, the loss of Round trailing edges thicker than $5.5 \%$ of throat is higher than that of the equivalent size Square trailing edges in the Isolated Trailing Edge Rig (see Fig. 8). For the trailing edges smaller than 5.5\% of throat the boundary layers are sufficiently thick to restrain the strength of transonic vortex shedding, and the Round trailing edges have lower loss than Square trailing edges, as is normally observed for trailing edges experiencing subsonic vortex shedding [5].

Figure 17 shows a sequence of Schlieren images arranged at equal time intervals around the shedding cycle of a Square trailing edge (of te/o $=7.8 \%$ ) in the Isolated Trailing Edge Rig, at Mach 0.70. Compared to Fig. 2, Fig. 9, or Fig. 10, showing Round trailing edges, the most significant difference is that the sharp corners of the Square trailing edge fix the locations of the separation points of the shear layers. As a result, the vortices form from each corner behind the Square trailing edge, whereas for Round trailing edges the vortices form near to the center of the base region when transonic vortex shedding is occurring.

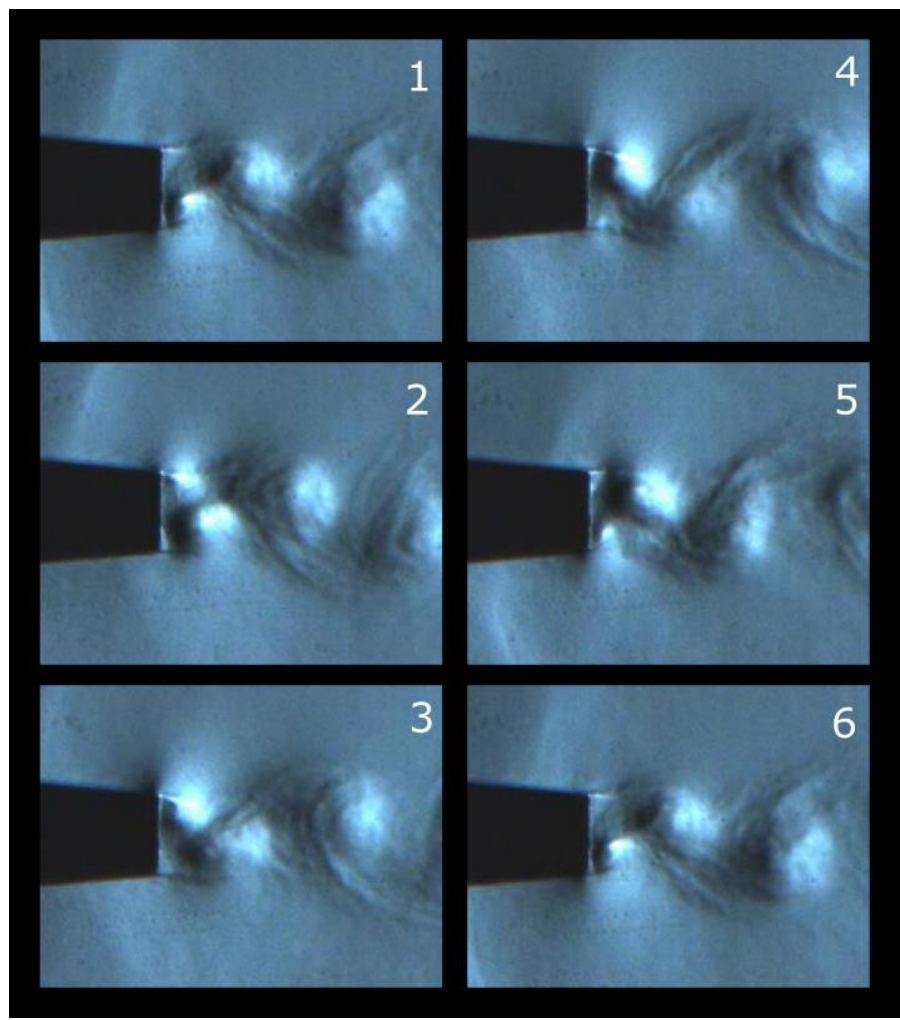

Fig. 17 - Schlieren images spaced at equal time intervals around a vortex shedding cycle, behind a Square trailing edge (of te/o $=7.8 \%$ ) at Mach 0.70 . Image 6 is a repeat image at the same phase as image 1.

The limitations that the sharp corners of Square trailing edges impose on the vortex shedding cycle limit the magnitude of the changes that occur in the flow field when transonic vortex shedding starts to occur behind square trailing edges, thus the maximum increase in loss that transonic vortex shedding can cause is limited for Square trailing edges. In contrast, for Round trailing edges, transonic vortex shedding is able to increase the magnitude of the motion of the shear layers more, and thereby strengthen vortex shedding and increase the loss more. Figure 18, which plots $\zeta / \zeta_{\mathrm{BL}}$ against te/ $\Sigma \theta$ for the Isolated Trailing Edge Rig Square trailing edges, supports this argument. Where the loss of Round trailing edges (Fig. 16) continues to grow as the trailing edges get thicker relative to the boundary layers up to at least $\operatorname{te} / \Sigma \theta \approx 20$, for Square trailing edges (Fig. 18) the rate of loss increase with increasing trailing edge thickness reduces for trailing edges thicker than te $/ \Sigma \theta \approx$ 10. This implies that, in the Isolated Trailing Edge Rig, above te $/ \Sigma \theta \approx 10$ the sharp corners of the Square trailing edges become limiting. 


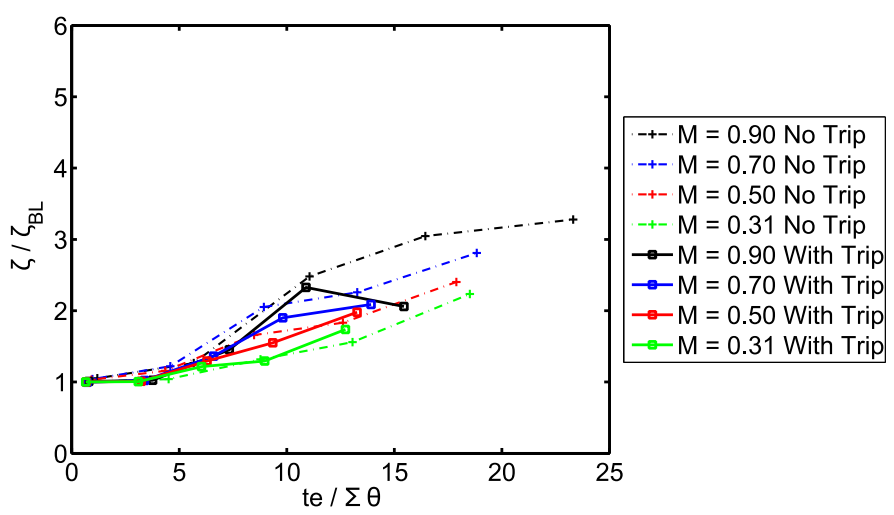

Fig. 18 - Trailing edge loss $\left(\zeta_{\text {te }}\right)$ plotted against te/o for the Isolated Trailing Edge Rig Square trailing edges, with and without a suction surface trip-wire.

Isolated Trailing Edge Rig Elliptical Trailing Edges

Under almost all conditions tested Elliptical trailing edges have lower loss than Square or Round trailing edges (see Fig. 8 and Fig. 12). At Mach numbers below 0.55, when transonic vortex shedding does not occur, the loss advantage of Elliptical trailing edges is relatively small, typically at most $20 \%$ of the overall loss. When transonic vortex shedding is occurring for Square and Round trailing edges, much larger loss advantages are measured for the Elliptical trailing edges, reaching $80 \%$ of the overall loss in the Isolated Trailing Edge Rig, at Mach 0.90 for the thickest trailing edge tested ( $7.8 \%$ of throat).

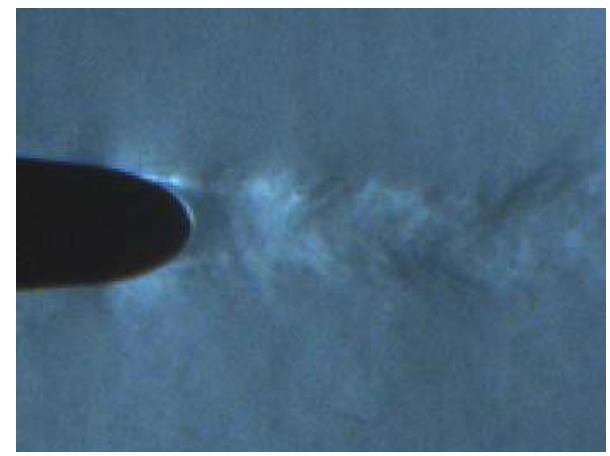

Fig. 19 - Schlieren image of the Elliptical trailing edge of te/o $=7.4 \%$ in the Isolated Trailing Edge Rig, at Mach 0.70.

Figure 19 shows a Schlieren image of the $7.4 \%$ of throat Elliptical trailing edge in the Isolated Trailing Edge Rig at Mach 0.70. Figure 19 shows that the shear layers separating from either side of the Elliptical trailing edge remain stable, and do not roll up into vortices until approximately a trailing edge thickness downstream of the trailing edge, leaving a small "dead air" region. This means the vortices do not interact directly with the trailing edge, and transonic vortex shedding does not occur.

Figure 20 shows $\zeta / \zeta_{\mathrm{BL}}$ plotted against te $/ \Sigma \theta$ for the Isolated Trailing Edge Rig Elliptical trailing edges. Figure 20 confirms that the loss of the Elliptical trailing edge remains at levels typical of subsonic or boundary layer dominated vortex shedding up to at least Mach 0.90, and trailing edge to sum boundary layer momentum thickness ratios up to approximately 20

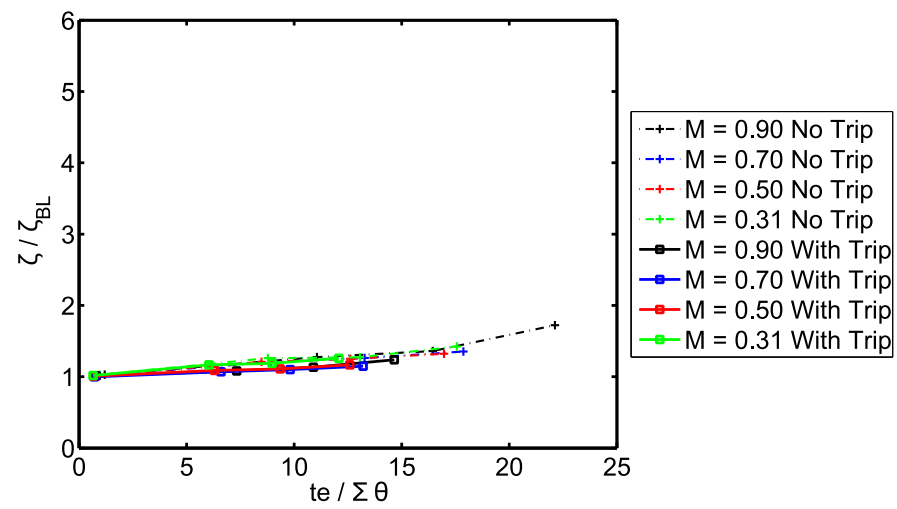

Fig. 20 - Trailing edge loss $\left(\zeta_{\text {te }}\right)$ plotted against te/o for the Isolated Trailing Edge Rig Elliptical trailing edges, with and without a suction surface trip-wire.

\section{INFLUENCE OF CASCADE RIG TRAILING EDGE SHAPES AND BOUNDARY LAYERS}

At the maximum inlet stagnation pressure (2.0 bar, corresponding to $\mathrm{Re}_{2}=2.6 \times 10^{6}$ at $\mathrm{M}_{2 \text {,mix }}=0.90$ ), as plotted on Fig. 12, the behavior of the Cascade Rig trailing edges is very similar to the Isolated Trailing Edge Rig trailing edges on Fig. 8. The thicker $16.2 \%$ of throat trailing edges behave similarly to the Isolated Trailing Edge Rig trailing edges of te/o $>5.5 \%$, with transonic vortex shedding occurring, and the Round trailing edge loss overtaking the loss of the Square trailing edge for Mach numbers over 0.80 . The thinner $8.1 \%$ of throat Cascade Rig trailing edges are boundary layer dominated and behave like the Isolated Trailing Edge Rig trailing edges of te/o $<5.5 \%$. The trailing edge thicknesses relative to the throat at which the trailing edges cease to be boundary layer dominated are different between the Isolated Trailing Edge Rig and the Cascade Rig as the blades in the two rigs do not have the same boundary layer thicknesses.

Figure 21 shows the evolution of the loss of the $16.2 \%$ of throat Cascade Rig trailing edges as the Reynolds number is varied. At a Reynolds number of $2 \times 10^{6}$ transonic vortex shedding abruptly starts to occur behind the $16.2 \%$ of throat Round trailing edge, as shown in the Schlieren images in Fig. 22, which shows images taken either side of the change.

To allow comparison to the results of Sieverding and Heinemann [12], a point Schlieren photometry technique following Bryanston-Cross and Camus [22] was used to measure the vortex shedding frequency. At Reynolds numbers below $2 \times 10^{6}$ a Strouhal number of 0.29 was measured, while at Reynolds numbers above $2 \times 10^{6}$ a Strouhal number of 0.19 was measured. Sieverding and Heinemann found that for Round trailing edges if both the pressure and suction surface boundary layers are turbulent the Strouhal number is below 0.25 . If both boundary layers are laminar the Strouhal number is between 0.30 and 0.40 . For mixed boundary layers (one laminar, one 
turbulent) the Strouhal number took an intermediate value, between 0.25 and 0.30 . Sieverding and Heinemann confirmed these results at Mach numbers up to Mach 0.90 .

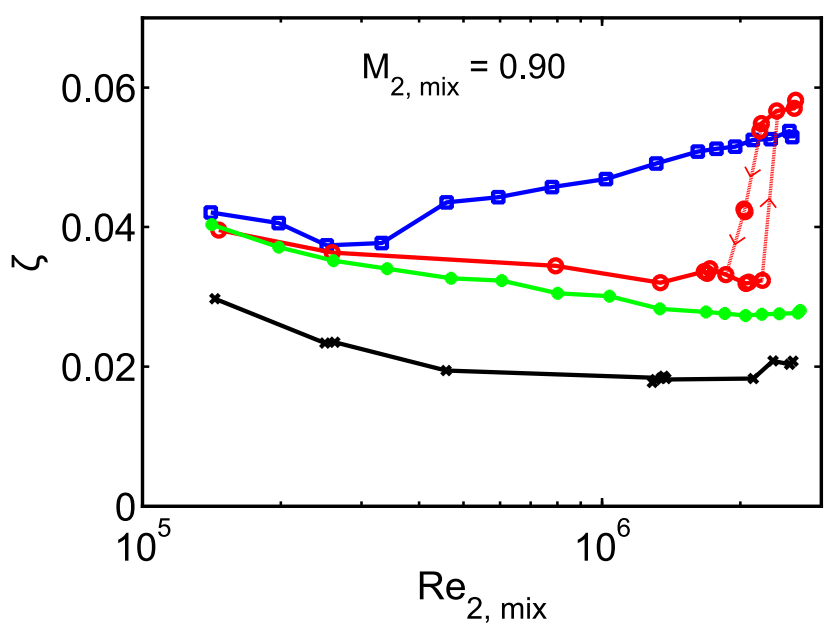

$\rightarrow$ Square $16 \% \rightarrow$ - Round $16 \% \multimap$ Ellipse $16 \% \rightarrow$ - Sharp

Fig. 21 - Plot of loss against exit Reynolds number at $\mathbf{M}_{2, \mathrm{mix}}=$ $\mathbf{0 . 9 0}$, for the $\mathbf{1 6 . 2 \%}$ of throat Cascade Rig trailing edges. The Sharp trailing edge is included for reference

Therefore, from Sieverding and Heinemann's [12] results it is inferred that the sudden change in flow structure and loss is due to the presence of a laminar-turbulent transition in one of the boundary layers, while the other boundary layer is turbulent. The transitioning boundary layer must be the pressure side boundary layer, as the flow on the pressure side is accelerating along its entire length, holding the pressure side boundary layer laminar to higher Reynolds numbers than the suction side boundary layer, which experiences a rapid acceleration followed by a gradual diffusion.

Figure 21 shows that the inferred laminar pressure surface boundary layer does not prevent transonic vortex shedding from the Square trailing edge, for which transonic vortex shedding persists down to a Reynolds number of $3 \times 10^{5}$. This is in agreement with Sieverding and Heinemann's [12] study, which concluded that Square trailing edges had "a similar effect on the Strouhal number as a large increase in the Reynolds number" compared to a Round trailing edge.

Figure 23 shows Schlieren images of the $16.2 \%$ of throat Square trailing edges in the Cascade Rig. On the left, the Square trailing edges are shown at a Reynolds number of $2.5 \times 10^{5}$, prior to the onset of transonic vortex shedding. The light beam deflections imaged by the Schlieren apparatus are related to the density of the flow [23], such that at this low Reynolds number condition, and therefore low density, the deflections are small, barely more than those caused by striations in the glass windows. It can just be discerned in this image that stable separations form from the trailing edge, that roll up into vortices about one trailing edge thickness downstream of the trailing edge. This is very similar to the flow seen behind the $16.2 \%$ of throat Round trailing edges prior to the onset of transonic vortex shedding in Fig. 22. On the right of Fig. 23 the $16.2 \%$ of throat Square trailing edge blades are shown at a Reynolds number of $2.6 \times 10^{6}$, clearly exhibiting transonic vortex shedding.

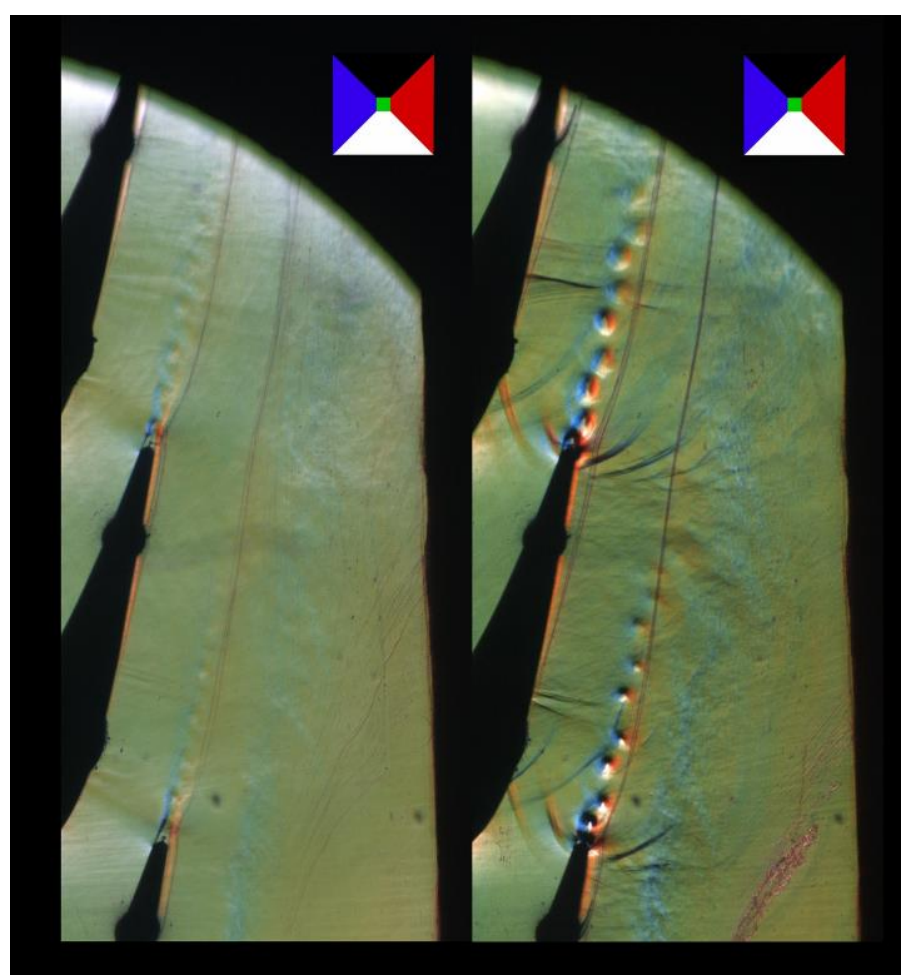

Fig. 22 - Schlieren images of the $16.2 \%$ of throat Round trailing edge blades in the Cascade Rig, at $M_{2, \text { mix }}=0.90$. Left $\operatorname{Re}_{2}=1.3 \times 10^{6}$, Right $-\operatorname{Re}_{2}=2.6 \times 10^{6}$

In accord with the Isolated Trailing Edge Rig results, the Elliptical trailing edges in the Cascade Rig were never observed to exhibit transonic vortex shedding. As a result, the loss level of the Elliptical trailing edges stays at that expected for subsonic vortex shedding, such that the $16.2 \%$ of throat Elliptical trailing edged blades have loss that is approximately half the loss of the same size Square or Round trailing edge blades, at Reynolds numbers over $2 \times 10^{6}$ on Fig. 21. Figure 24 shows a Schlieren image of the $16.2 \%$ of throat Elliptical trailing edge, at a Reynolds number of $2.6 \times 10^{6}$. Stable separations are observed, with vortices only forming approximately a trailing edge diameter downstream of the trailing edge. This is similar to the $16.2 \%$ of throat Round trailing edge at Reynolds numbers below $2 \times 10^{6}$, or the same size Square trailing edge at Reynolds numbers below $3 \times 10^{5}$.

Figure 25 plots the kinetic energy loss of the smaller $8.1 \%$ of throat Cascade Rig trailing edges against Reynolds number, again at Mach 0.90. The Cascade Rig boundary layers were sufficiently thick to prevent transonic vortex shedding from the $8.1 \%$ of throat trailing edges, such that the trailing edge loss remains less than a third of the overall loss, and the Elliptical trailing edge has a smaller loss advantage over the other geometries. 


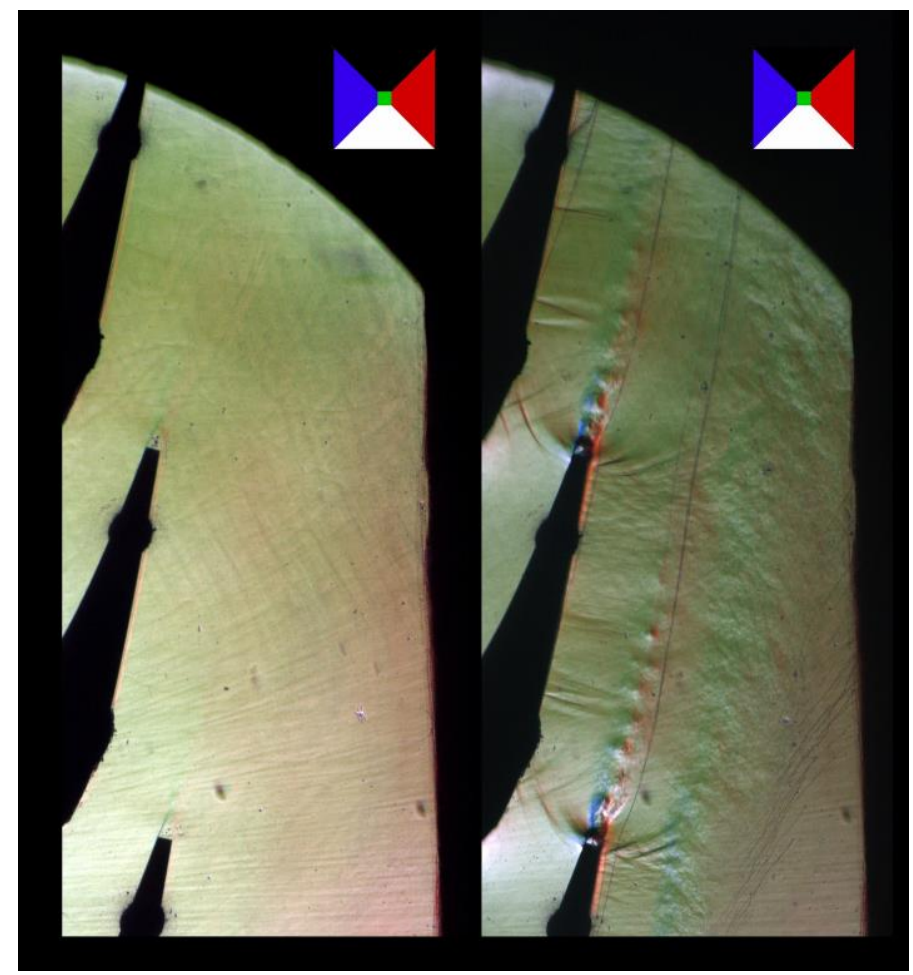

Fig. 23 - Schlieren images of the $16.2 \%$ of throat Square trailing edge blades in the Cascade Rig, at $M_{2, \operatorname{mix}}=0.90$. Left $\operatorname{Re}_{2}=2.5 \times 10^{5}$, Right $-\operatorname{Re}_{2}=2.6 \times 10^{6}$

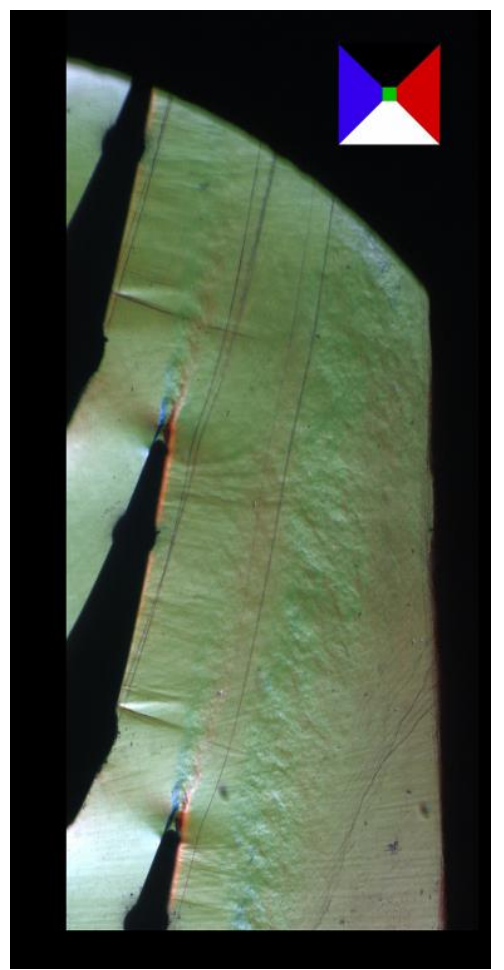

Fig. 24 - Schlieren image of the $16.2 \%$ of throat Elliptical trailing edge blades in the Cascade Rig, at $M_{2, \text { mix }}=0.90, R_{2}=$ $2.6 \times 10^{6}$.

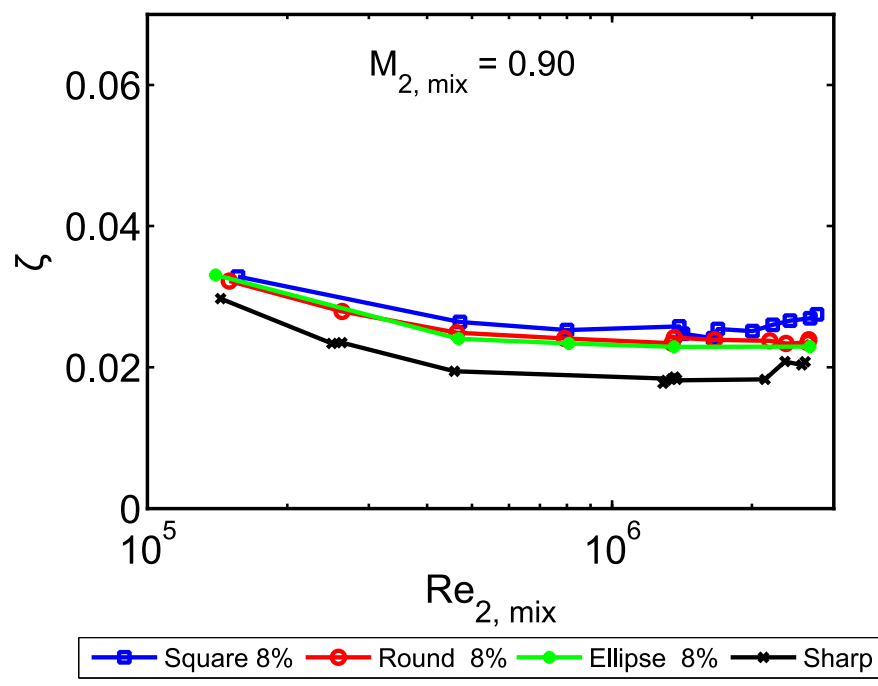

Fig. 25 - Plot of loss against exit Reynolds number at $\mathbf{M}_{\mathbf{2}}$, mix = 0.90, for the $\mathbf{8 . 1 \%}$ of throat Cascade Rig trailing edges. The Sharp trailing edge is included for reference

Comparison between Isolated Trailing Edge Rig and Cascade $\underline{\text { Rig Trailing Edges }}$

Qualitatively the Cascade Rig results are in good agreement with the results of the Isolated Trailing Edge Rig. In particular, in both rigs Shockwave interference is observed to affect the loss of trailing edges exhibiting transonic vortex shedding, thicker boundary layers relative to the trailing edge are observed to suppress transonic vortex shedding, and Elliptical trailing edges are effective at suppressing transonic vortex shedding.

To assess the quantitative agreement between the two rigs Fig. 26 plots overall loss normalized by the loss of the sharp blade against the trailing edge thickness, also normalized by the sharp blade loss, for all the tests performed at Mach 0.90 in both rigs. The loss of the sharp trailing edge is used instead of the sum boundary layer momentum thickness used on Figs 16, 18 , and 20, as boundary layer traverses were not available for the Cascade Rig blades. For the Cascade Rig data, at values of (te/o) $/ \zeta_{\text {sharp }}>7.5$, two values of loss are present for each value of (te/o)/ $/ \zeta_{\text {sharp }}$; this occurs because the loss of the sharp blade rises at exit Reynolds numbers over $2 \times 10^{6}$, due to the inferred transition to turbulence on the pressure surface at this Reynolds number

The onset of transonic vortex shedding for the Cascade Rig trailing edges on Fig. 26 is delayed to higher trailing edge thickness to boundary layer ratios, compared to the Isolated Trailing Edge Rig results. There are several potential explanations for this discrepancy between the two rigs. First, the boundary layers in the two rigs are different, those in the Isolated Trailing Edge Rig were always turbulent or transitional, whereas those in the Cascade Rig are laminar at some conditions. In addition, whereas with the suction surface trip wire present in the Isolated Trailing Edge Rig the suction 
surface boundary layer was approximately twice the thickness of the pressure surface boundary layer, the boundary layer asymmetry is thought to be much greater in the Cascade Rig: a crude estimate of the suction surface boundary layer being approximately 6 times thicker than the pressure surface boundary layer in the Cascade Rig can be obtained by making measurements on the Schlieren images. Further, shockwave reflections are only present on the pressure side of the Cascade Rig trailing edges, whereas they are present on both sides in the Isolated Trailing Edge Rig.

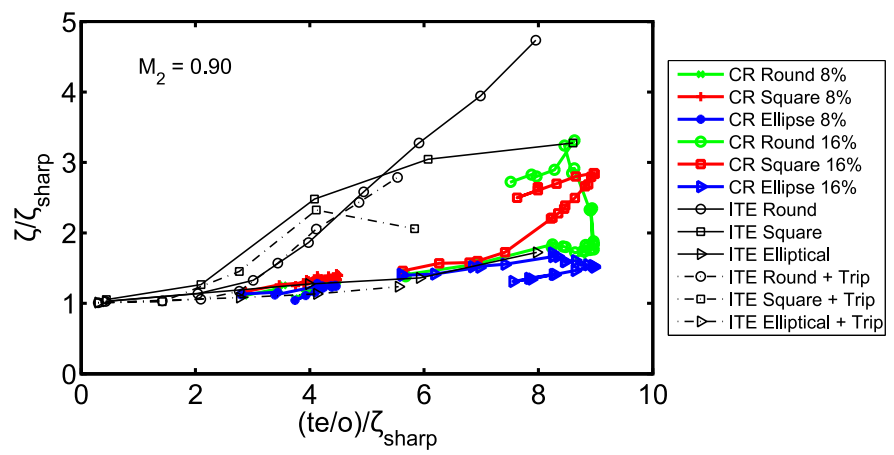

Fig. 26 - Plot of overall loss normalized by the loss of the sharp blade against the trailing edge thickness normalized by the loss of the sharp blade, for all trailing edges tested at Mach 0.90.

The increased asymmetry (both of the boundary layers and reflected shockwaves), and presence of laminar boundary layers, are thought to cause the quantitative differences seen on Fig. 26. In the presence of laminar boundary layers, and boundary layers with high asymmetry, a more advanced characterization of the boundary layers than (te/o) $/ \zeta_{\text {sharp }}$ or te $/ \Sigma \theta$ is therefore thought to be necessary to capture the effects of the boundary layers on the onset of transonic vortex shedding. Overall, it is still the case that no trailing edge with sum boundary layer momentum thicknesses greater than $1 / 7^{\text {th }}$ of the trailing edge thickness has been observed to exhibit transonic vortex shedding in the present work, and so this may still be a useful criterion for the onset of transonic vortex shedding, similar to the use of critical Reynolds numbers for judging the likelihood of laminar to turbulent transition in boundary layers.

\section{CONCLUSIONS}

1. Transonic vortex shedding, which occurs due to the separated shear layers reaching supersonic Mach numbers during the vortex shedding cycle, is responsible for large increases in the loss of blunt trailing edges at Mach numbers over 0.55. Certain blades with trailing edges that exhibit transonic vortex shedding have been measured to have twice the loss of blades with the same thickness trailing edges that suppress transonic vortex shedding.

2. The reflections of shed shockwaves from an adjacent blade (or other wall), originating from transonic vortex shedding, have been shown to be capable of encouraging or discouraging vortex shedding, depending on whether the motion of the shockwave reflections is in phase with the motion of the trailing edge shear layers when the shockwaves return. This phenomenon has been observed to cause peaks and troughs in the loss of trailing edges that exhibit transonic vortex shedding.

3. The boundary layers at the trailing edge have a strong influence over the flow structure and loss downstream of the trailing edge. All blades measured with sum boundary layer momentum thicknesses greater than $1 / 7^{\text {th }}$ of the trailing edge thickness did not exhibit increased loss due to transonic vortex shedding, presumed to be due to the dampening effect of the boundary layers on the trailing edge flow. The presence of a laminar pressure surface boundary layer has also been found to suppress transonic vortex shedding from Round trailing edges but not Square trailing edges.

4. Square trailing edges have been found to partially restrict transonic vortex shedding due to sharp corners fixing the shear layer separation points. As a result, certain Square trailing edges can have lower loss than the same size Round trailing edge, when both are exhibiting transonic vortex shedding.

5. 2:1 major to minor ratio Elliptical trailing edges have been found to be capable of suppressing transonic vortex shedding, giving considerable loss advantages over Square or Round trailing edges if the Square or Round trailing edges are exhibiting transonic vortex shedding.

\section{Acknowledgments}

The authors would like to thank Fred Goenaga and Mark Stokes of Rolls-Royce plc for their advice and technical support. The assistance of Mark Furbank and Nick Atkins, of the Whittle Laboratory, is also gratefully acknowledged. This work was funded by Rolls-Royce plc under Innovate UK's SILOET II programme.

\section{Nomenclature}

$\begin{aligned} \frac{\text { Symbols }}{\mathrm{CR}} & =\text { Cascade Rig } \\ \mathrm{E}_{\mathrm{k}} & =\text { Kinetic Energy } \\ \mathrm{f} & =\text { frequency } \\ \mathrm{H} & =\text { Boundary layer shape factor } \\ \mathrm{ITR} & =\text { Isolated Trailing edge Rig } \\ \mathrm{KE} & =\text { Kinetic Energy } \\ \mathrm{M} & =\text { Mach number } \\ \mathrm{O} & =\text { Throat width } \\ \mathrm{P} & =\text { Pressure } \\ \mathrm{Re} & =\text { Reynolds number } \\ \mathrm{St} & =\text { Strouhal number (f*te/U) } \\ \theta & =\text { Boundary layer momentum thickness }\end{aligned}$




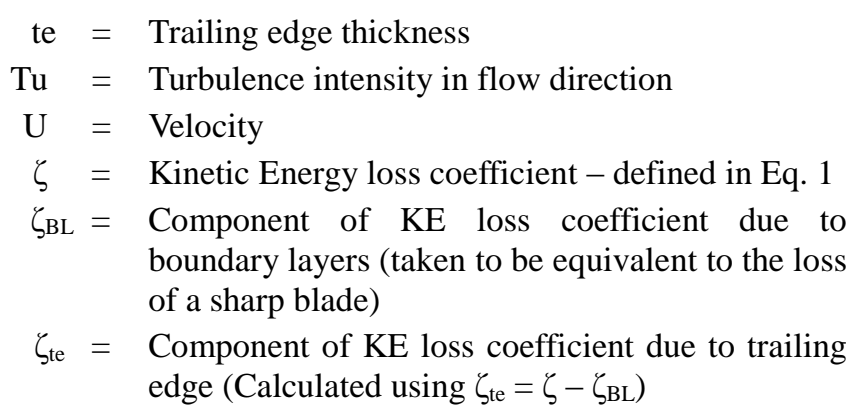

$\underline{\text { Subscripts }}$

$\begin{aligned} \text { ax } & =\text { Axial } \\ \mathrm{BL} & =\text { Boundary layer } \\ \text { is } & =\text { Isentropic } \\ \max & =\text { Maximum } \\ \operatorname{mix} & =\text { Mixed out } \\ \text { harp } & =\text { Of a sharp trailing edge } \\ \text { te } & =\text { At the trailing edge } \\ 0 & =\text { Stagnation quantity } \\ 1 & =\text { Inlet } \\ 2 & =\text { Exit }\end{aligned}$

\section{REFERENCES}

[1] Hoerner, S.F., 1965, "Fluid-dynamic drag : practical information on aerodynamic drag and hydrodynamic resistance." S.F. Hoerner, New Jersey.

[2] Cicatelli, G., and Sieverding, C. H., 1997, "The Effect of Vortex Shedding on the Unsteady Pressure Distribution Around the Trailing Edge of a Turbine Blade." ASME J. Turbomach, Vol. 119, pp. 810-819, DOI: 10.1115/1.2841192.

[3] Lawaczeck, O and Heinemann, J., 1975, "Von Karman Vortex Street Wake of Subsonic and Transonic Turbine Nozzle Vanes." AGARD Conference Proceedings, AGARD CP-177.

[4] Nash, J.F., Quincey, V.G. and Callinan, J., 1963, "Experiments on Two-dimensional Base Flow at Subsonic and Transonic Speeds." Aeronautical Research Council Reports and Memoranda, No. 3427.

[5] Sutton, A. J., 1990, "The trailing edge loss of subsonic turbine blades." University of Cambridge MSc dissertation.

[6] Roberts, Q., 1997, "The trailing edge loss of subsonic turbine blades", University of Cambridge PhD dissertation.

[7] Denton, J. D., 1993, "The 1993 IGTI Scholar Lecture: Loss Mechanisms in Turbomachines." ASME J. Turbomach., Vol. 115(4), p. 621.

[8] Xu, L., and Denton, J. D., 1988, "The Base Pressure and Loss of a Family of Four Turbine Blades." ASME J. Turbomach. Vol. 110(1), p. 9.
[9] Sieverding, C. H., Richard, H., and Desse, J.-M., 2003 "Turbine Blade Trailing Edge Flow Characteristics at High Subsonic Outlet Mach Number.” ASME J. Turbomach., 125(2), pp. 298-309.

[10] Prust, H. W., and Helon, R., 1972, "Effect of trailing edge geometry and thickness on the performance of certain turbine stator blading." NASA technical note, NASA TN D-6637.

[11] Herbert, M. V., 1973, "A discussion on the prediction of profile loss for axial-flow turbine blades." Aeronautical Research Council Reports and Memoranda, No. 34757.

[12] Sieverding, C. H., and Heinemann, H., 1990, "The Influence of Boundary Layer State on Vortex Shedding From Flat Plates and Turbine Cascades." ASME J. Turbomach. Vol. 112(2), p. 181.

[13] Sieverding, C. H., 1983, "The Influence of Trailing Edge Ejection on the Base Pressure in Transonic Turbine Cascades." ASME J. Eng. for Power, 105, p.215.

[14] Xu, L., and Denton, J. D., 1987, "Base pressure measurements on a model of a turbine blade trailing edge." IMechE Paper No. C283/87.

[15] Deckers, M., and Denton, J. D., 1997, "Aerodynamics of trailing-edge-cooled transonic turbine blades: Part 1experimental approach.” ASME 1997 International Gas Turbine and Aeroengine Congress, Orlando, Florida, June 2-5, 97-GT518.

[16] Ower, E., and Pankhurst, R. C., 1977, "Measurement of air flow." Pergamon press.

[17] Willert, C., Stasicki, B., Klinner, J., and Moessner, S., 2010, "Pulsed operation of high-power light emitting diodes for imaging flow velocimetry." IOP Meas. Sci. Technol., Vol. 21.

[18] Gostelow, J. P., and Watson, P. J., 1976, "A Closed Circuit Variable Density Air Supply for Turbomachinery Research." ASME 1976 International Gas Turbine and Fluids Engineering Conference, New Orleans, Louisiana, March 21-25, 76-GT-62.

[19] Sieverding, C.H., Maretto, L., Lehthaus, and Lawaczeck, O., 1974, "Design and Calibration of Four Probes for use in the Transonic Turbine Cascade Testing." Von Karman Institute, Technical Note 100.

[20] Dominy, R.G., and Hodson H.P., 1993, "An Investigation of Factors Influencing the Calibration of Five-Hole Probes for Three-Dimensional Flow Measurements." ASME J. Turbomach., 115, p. 513.

[21] Gostelow, J. P., 1984, "Chapter 8 - Stalled and Unsteady Flows." Cascade Aerodynamic, Pergamon Press, p. 173,

[22] Bryanston-Cross, P. J., and Camus, J.J., 1982, "Auto and Cross Correlation Measurements in a Turbine Cascade Using a Digital Correlator.” ASME 1982 International Gas Turbine Conference, London, England, April 18-22, 82-GT-132.

[23] Settles, G.S., 2001, "2 - Basic Concepts." Schlieren and Shadowgraph Techniques, Springer-Verlag. 